\title{
Discovery of Potent and Noncovalent Reversible EGFR Kinase Inhibitors of EGFR ${ }^{L 858 R / T 790 M / C 7975}$
}

Qiannan Li, ${ }^{\dagger, \S}$ Tao Zhang, ${ }^{\ddagger, \S}$ Shiliang Li, ${ }^{\dagger, \S \odot ~ L i n j i a n g ~ T o n g, ~}{ }^{\ddagger}$ Junyu Li, ${ }^{\dagger}$ Zhicheng Su, $^{\dagger}$ Fang Feng, ${ }^{\ddagger}$ Deheng Sun, ${ }^{\dagger}$ Yi Tong, ${ }^{\dagger}$ Xia Wang, ${ }^{\dagger}$ Zhenjiang Zhao, ${ }^{\dagger}$ Lili Zhu, ${ }^{\dagger}$ Jian Ding, ${ }^{\ddagger}$ Honglin Li, ${ }^{*}, \dagger$ Hua Xie, ${ }^{*},+$ and Yufang $\mathrm{Xu}^{*} \dagger$

${ }^{\dagger}$ Shanghai Key Laboratory of New Drug Design, State Key Laboratory of Bioreactor Engineering, School of Pharmacy, East China University of Science and Technology, Shanghai 200237, China

${ }^{\ddagger}$ Division of Anti-tumor Pharmacology, State Key Laboratory of Drug Research, Shanghai Institute of Materia Medica, Chinese Academy of Sciences, Shanghai 201203, China

Supporting Information

ABSTRACT: In this paper, we describe the discovery and optimization of a series of noncovalent reversible epidermal growth factor receptor inhibitors of $\mathrm{EGFR}^{\mathrm{L} 858 \mathrm{R} / \mathrm{T} 790 \mathrm{M} / \mathrm{C} 797 \mathrm{~S}}$. One of the most promising compounds, 25g, inhibited the enzymatic activity of $\mathrm{EGFR}^{\mathrm{L} 858 \mathrm{R} / \mathrm{T} 790 \mathrm{M} / \mathrm{C} 797 \mathrm{~S}}$ with an $\mathrm{IC}_{50}$ value of $2.2 \mathrm{nM}$. Cell proliferation assays showed that $25 \mathrm{~g}$ effectively and selectively inhibited the growth of

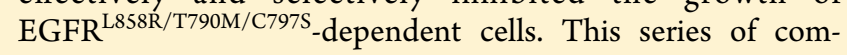
pounds, which occupy both the ATP binding site and the allosteric site of the EGFR kinase, may serve as a basis for the development of fourth-generation EGFR inhibitors for L858R/T790M/C797S mutants.

KEYWORDS: EGFR, mutant, inhibitor, C797S

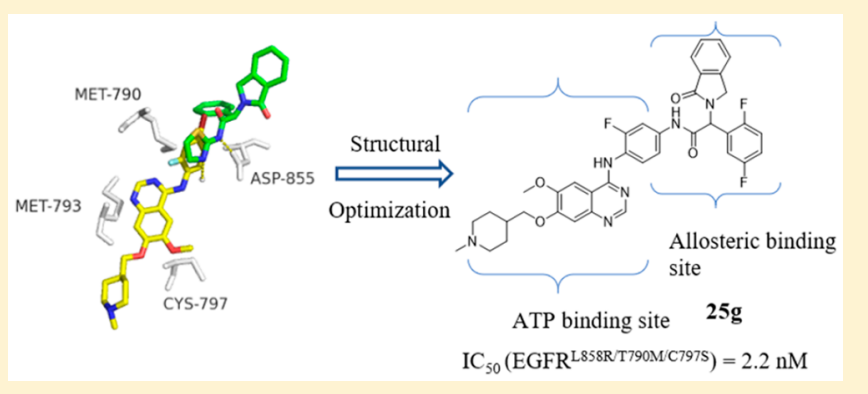

\section{INTRODUCTION}

Epidermal growth factor receptor (EGFR), a member of the HER family, is an essential transmembrane glycoprotein in cell signaling pathways that regulate cell proliferation, differentiation, and apoptosis. ${ }^{1}$ The overexpression of EGFR has been observed in many types of solid tumors. ${ }^{2-4}$ Nonsmall cell lung cancer (NSCLC) is one of the most malignant cancer types worldwide. ${ }^{5}$ With the drug development, various small molecular EGFR inhibitors (Figure S1, Supporting Information) have been developed as therapeutic agents for NSCLC.

The first generation of reversible EGFR inhibitors, gefitinib and erlotinib, delivered significant therapeutic effects for NSCLC patients with activating EGFR mutations. ${ }^{6-8}$ The L858R point mutation and exon 19 deletion are the most common activating mutations, with enhanced sensitivity to inhibitors. ${ }^{9}$ However, after 12 months of clinical treatment, the T790M mutation appeared in 50\%-60\% of drug-resistant patients. ${ }^{10}$ The presence of T790M increases the affinity of the receptor for ATP, thereby reducing the ability of EGFR inhibitors to effectively compete with ATP. ${ }^{11}$ Then, the second- and third-generation EGFR irreversible inhibitors were developed $^{12}$ that had increasing cellular potency against T790M mutants, mainly by covalently binding to $\mathrm{Cys}_{797 .}{ }^{13}$ However, because the aniline moiety of the second-generation EGFR inhibitors may not interact as effectively with the side chain of $\mathrm{Met}_{790}$, the T790M activity is lower against the activating EGFR mutations. ${ }^{14}$ The third-generation EGFR inhibitors selectively and irreversibly target $\mathrm{EGFR}^{\mathrm{T} 790 \mathrm{M}}$ and other activated EGFR mutations. AZD9291 (4, osimertinib, Figure S1, Supporting Information) ${ }_{17}^{15,16}$ the only FDA approved third generation inhibitor, ${ }^{17}$ has good potency against the EGFR ${ }^{\mathrm{T} 790 \mathrm{M}}$ mutant and minimal toxicities, with excellent selectivity for wild-type EGFR. Nevertheless, a clinical study showed that $20-30 \%$ of patients treated with AZD9291 developed the tertiary point mutation C797S, ${ }^{18}$ which prevents irreversible inhibitors from covalently binding to $\mathrm{Cys}_{797}$. Loss of the covalent interaction results in a marked decrease in inhibition, which then leads to the development of resistance.

Jia et al. reported on compound EAI001 (6, Figure S1, Supporting Information) as the first non-ATP competitive $\mathrm{EGFR}^{\mathrm{L} 858 \mathrm{R} / \mathrm{T} 790 \mathrm{M} / \mathrm{C} 797 \mathrm{~S}}$ inhibitor. ${ }^{19}$ After structural optimization, a more potent compound 1 (EAI045, Figure 1) was obtained. EAI045 binds to the allosteric site created by the outward displacement of the $\alpha \mathrm{C}$-helix of the EGFR kinase, located next to the ATP binding pocket. ${ }^{19}$ The discovery of this allosteric site laid the theoretical foundation for our research.

Received: November 21, 2018

Accepted: May 21, 2019

Published: May 22, 2019 


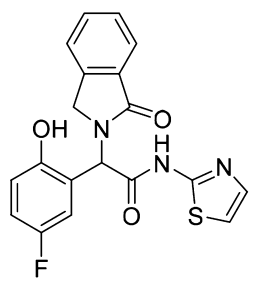

1 (EAI045)

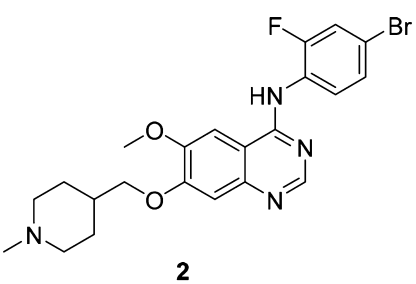

2
Figure 1. Structures of compound 1 (EAI045) and compound 2.

We found that compound 2 (2, Figure 1), a known EGFR inhibitor (vandetinib), ${ }^{20}$ exhibited modest potency $\left(\mathrm{IC}_{50}=\right.$ $369.2 \mathrm{nM}$ ) against the $\mathrm{EGFR}^{\mathrm{L} 858 \mathrm{R} / \mathrm{T} 790 \mathrm{M} / \mathrm{C} 797 \mathrm{~S}}$ mutant. Both the reference $^{21}$ and our molecular docking simulation (gscore = $-8.2 \mathrm{kcal} / \mathrm{mol}$ ) indicated that compound 2 could extend into the ATP binding pocket of EGFR (Figure 2A). Inspired by the binding model of EAI045, we attempted to modify 2 to occupy both the ATP binding site and the allosteric site of the EGFR kinase, with the aim of enhancing the binding affinity of the inhibitor to EGFR ${ }^{\mathrm{L} 858 \mathrm{R} / \mathrm{T} 790 \mathrm{M} / \mathrm{C} 797 \mathrm{~S}}$, to effectively compete with ATP and thus overcome resistance. Then, 25a was developed (Figure 2B). Based on 25a, we designed and synthesized a series of novel, highly potent, and noncovalent reversible inhibitors of EGFR ${ }^{\mathrm{L} 858 \mathrm{R} / \mathrm{T} 790 \mathrm{M} / \mathrm{C} 797 \mathrm{~S}}$ and explored their structure-activity relationships. In this study, one of the most promising compounds is $\mathbf{2 5 g}$ (Figure 2B), which inhibited the enzymatic activity of $\mathrm{EGFR}^{\mathrm{L} 858 \mathrm{R} / \mathrm{T} 790 \mathrm{M} / \mathrm{C} 797 \mathrm{~S}}$ with an $\mathrm{IC}_{50}$ value of $2.2 \mathrm{nM}$. Cell proliferation assays showed that $\mathbf{2 5 g}$ effectively and selectively inhibited the growth of

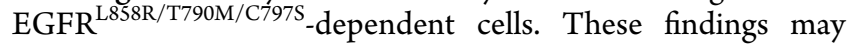
help overcome acquired resistance to third-generation EGFR inhibitors.

\section{RESULTS AND DISCUSSION}

The docking model of 2 with EGFR ${ }^{\mathrm{T} 790 \mathrm{M} / \mathrm{V} 948 \mathrm{R}}$ shows that 2 binds at the ATP binding site of EGFR with its phenyl group occupying a position similar to that of the thiazole moiety of EAI001 (Figure 2A). EAI001 binds as a "Y shaped" configuration in the allosteric site. ${ }^{22}$ Modifying 2 to occupy both the ATP binding site and the allosteric site may be a promising way to increase the bioactivity against the EGFR $^{\text {L858R/T790M/C797S }}$ triple mutant.

To facilitate the occupation of the allosteric site of EGFR, different hydrophobic groups were introduced to the $\mathbf{R}^{1}$ position of 2 with an amide bond as the linker. The resultant compounds, 18a-18i (Figure 2C), had no inhibitory activity against EGFR ${ }^{\mathrm{L} 858 \mathrm{R} / \mathrm{T} 790 \mathrm{M} / \mathrm{C} 797 \mathrm{~S}}$ (Table S1, Supporting Information). Referring to the structure of EAI045, oxoisoindolin-2phenylacetamide was introduced into the $\mathbf{R}^{\mathbf{1}}$ position, synthesizing compound 25a. The kinase assay showed that 25a has a nanomolar level bioactivity $\left(\mathrm{IC}_{50}=9.3 \mathrm{nM}\right)$ against $\mathrm{EGFR}^{\mathrm{L} 858 \mathrm{R} / \mathrm{T} 790 \mathrm{M} / \mathrm{C} 797 \mathrm{~S}}$. We surmised that the substituted group at the $\mathbf{R}^{\mathbf{1}}$ position of $\mathbf{2 5 a}$ has a "Y-shaped" configuration, ${ }^{22}$ making it more likely to embed in the allosteric site. To further explore the structure-activity relationship and acquire compounds with higher potency, we selected compound 25a as the new lead compound.

After a docking simulation, we found that the interactions between 25a and EGFR include three parts (Figure 2C and Figure 3): (1) the quinazoline scaffold of 25 a forms a

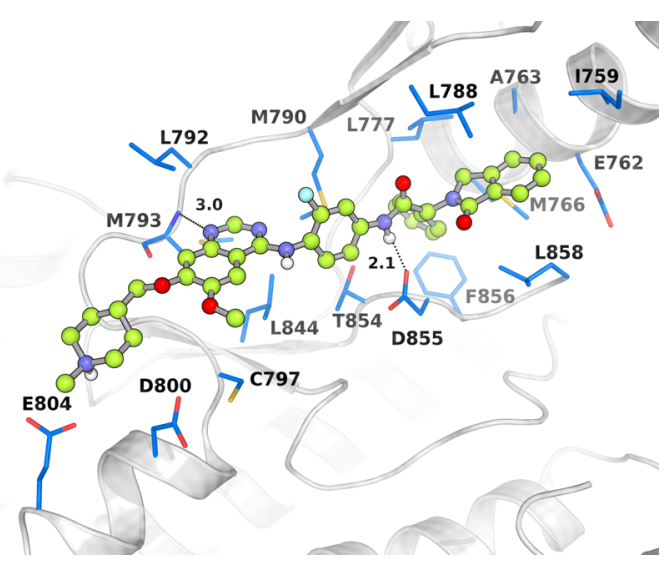

Figure 3. Docked pose of compound 25a. The EGFR protein (PDB: $5 \mathrm{~d} 41$ ) is shown as a gray cartoon, and the key residues are shown as blue sticks. Key H-bonds are displayed as black dashes and measured by distances. The figure was generated using Pymol 1.3.

hydrogen bond with residue Met793 in the hinge region; (2) the "Y-shaped" $\mathbf{R}^{1}$ group oxoisoindolin-2-phenylacetamide extends into the EGFR kinase allosteric site with hydrophobic interaction; and (3) the alkoxy side chain $\mathbf{R}^{2}, \mathbf{R}^{3}$ of the quinoline scaffold faces toward the solvent-exposed region.

We then optimized 25a mainly from three aspects: (1) the allosteric region; (2) the hinge region; and (3) the solventexposed region.
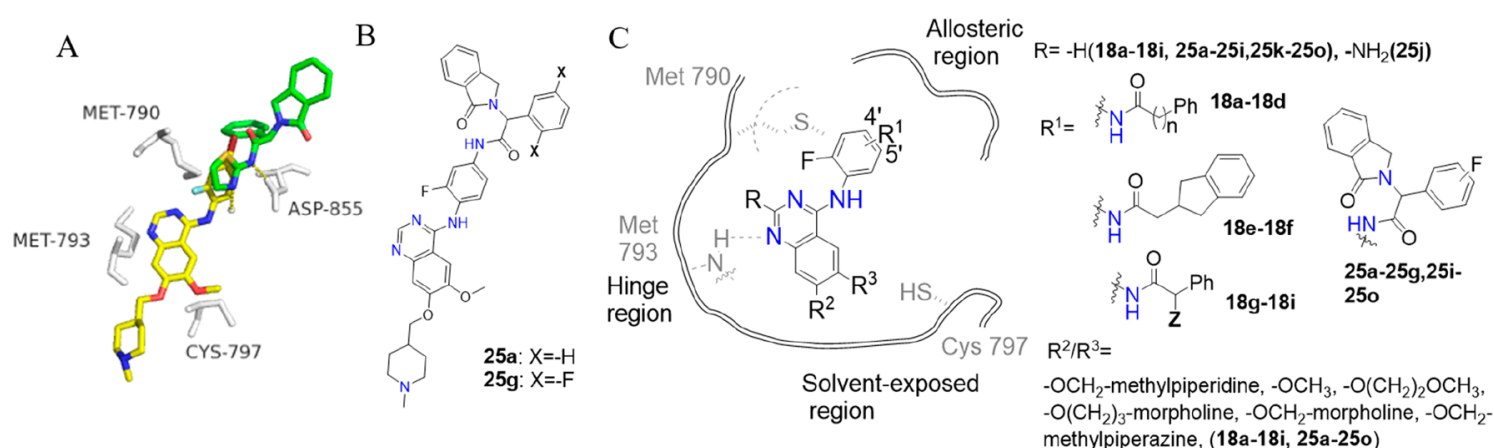

Figure 2. (A) Overlaid model of the docked pose of compound 2 (yellow) and the bound conformation of the allosteric inhibitor EAI001 (cyan) in $\mathrm{EGFR}^{\mathrm{T} 790 \mathrm{M} / \mathrm{V}_{94} 8 \mathrm{R}}$ (PDB: $5 \mathrm{~d} 41$ ), key residues are shown as gray sticks; (B) Chemical structures of compounds 25a and 25g; (C) The 2D interactions diagram for the quinazoline scaffold to show strategies of structural modifications, with chemical structures of the representative compounds. $n=0,1 ; \mathrm{Z}=-\mathrm{CH}_{3},-\mathrm{CH}\left(\mathrm{CH}_{3}\right)_{2},-\mathrm{Ph}$. 
In the allosteric region, "the Y-shaped" group oxoisoindolin2-phenylacetamide was introduced at the $\mathbf{R}^{1}$ position (Figure 2C). Compound 25b was first synthesized, and the "Y-shaped" group was attached to the ortho position ( $5^{\prime}$-position) of anilino-quinazoline. Compound $\mathbf{2 5 \mathbf { b }}$ displayed an $\mathrm{IC}_{50}$ value of $37.1 \mathrm{nM}$ against $\mathrm{EGFR}^{\mathrm{L} 858 \mathrm{R} / \mathrm{T} 790 \mathrm{M} / \mathrm{C} 797 \mathrm{~S}}$, a 4-fold decrease compared to that of 25a. Compounds $25 \mathrm{c}$ and its isomer $25 \mathrm{~d}$ exhibited $\mathrm{IC}_{50}$ values of $7.9 \mathrm{nM}$ and $19.2 \mathrm{nM}$, respectively, against $\mathrm{EGFR}^{\mathrm{L} 858 \mathrm{R} / \mathrm{T} 790 \mathrm{M} / \mathrm{C} 797 \mathrm{~S}}$. This result indicates that the Senantiomer is preferred over $\mathrm{R}$, but both are acceptable. Then, a fluorine atom was introduced to different positions of the phenyl to acquire $\mathbf{2 5 e}-\mathbf{2 5 g}$. Kinase assay results showed that $\mathbf{2 5 g}$ was the most potent, increasing the inhibitory activity by over 4-fold compared with $25 \mathrm{a}\left(\mathrm{IC}_{50}=2.2 \mathrm{nM}\right)$. The introduction of the two fluorine atoms plays a crucial role in strengthening the binding affinity. Replacing the phenyl group of 25a within a cyclohexane group led to compound 25h. Compound 25h displayed less potent inhibitory activity, with an $\mathrm{IC}_{50}$ value of $179.6 \mathrm{nM}$ against $\mathrm{EGFR}^{\mathrm{L} 858 \mathrm{R} / \mathrm{T} 790 \mathrm{M} / \mathrm{C} 797 \mathrm{~S} \text {, a }}$ significant decrease in activity compared with 25a, suggesting that the $\pi-\pi$ stacking interaction between the phenyl of the "Y-shaped" group and residue Phe856 of the hydrophobic allosteric cavity plays an important role in maintaining the bioactivities of this series against $\mathrm{EGFR}^{\mathrm{L} 858 \mathrm{R} / \mathrm{T} 790 \mathrm{M} / \mathrm{C} 797 \mathrm{~S}}$ (Figure 3).

In the hinge region, only one hydrogen-bond interaction can form between the quinazoline scaffold of 25a and Met793 (Figure 2C). To enhance the binding strength, we proposed that another hydrogen bond might be formed between the compound and Met793 by introducing a substituent at the $\mathbf{R}$ position containing a hydrogen bond donor such as $-\mathrm{NH} 2$; thus, 25j was synthesized. Kinase assay results showed that 25j displayed no inhibitory activity against either T790M/L858R or L858R/T790M/C797S mutant, indicating that "- $\mathrm{NH}_{2}$ ” was not tolerated at the $\mathrm{R}$ position.

In the solvent-exposed region, to investigate the effect of the

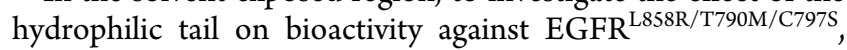
we performed structural derivatization using piperidine, morpholine, and alkyl chains at $\mathbf{R}^{2}$ or $\mathbf{R}^{3}$ to synthesize compounds $25 \mathbf{i}$ and $25 \mathbf{k}-\mathbf{o}$. The kinase inhibitory activities of these compounds were lower than that of 25a, which has an $\mathrm{IC}_{50}$ value of $9.3 \mathrm{nM}$ against EGFR ${ }^{\mathrm{L} 858 \mathrm{R} / \mathrm{T} 790 \mathrm{M} / \mathrm{C} 797 \mathrm{~S}}$ (Table S2, Supporting Information).

After a series of optimizations, compound $\mathbf{2 5 g}$, with the best kinase inhibitory activity against $\mathrm{EGFR}^{\mathrm{L} 858 \mathrm{R} / \mathrm{T} 790 \mathrm{M} / \mathrm{C} 797 \mathrm{~S} \text {, was }}$ obtained $\left(\mathrm{IC}_{50}=2.2 \mathrm{nM}\right)$. Like 25a, docking simulations suggested that $\mathbf{2 5 g}$ also occupies both the ATP binding site and the allosteric site (Figure 4), exhibiting similar intermolecular interactions.

The synthetic procedures of all compounds are shown in the Supporting Information (Schemes S1-S3).

The kinase profile of $\mathbf{2 5} \mathbf{g}$ across 37 kinases is shown in Figure 5. Treatment with $\mathbf{2 5 g}$ at $100 \mathrm{nM}$ demonstrated more than $90 \%$ inhibition of EGFR ${ }^{\mathrm{L} 858 \mathrm{R} / \mathrm{T} 790 \mathrm{M} / \mathrm{C} 797 \mathrm{~S}}$ as well as the EGFR family of kinases (ErbB2 and ErbB4) and BLK, and it exhibited moderate potency against Src, Abl, PDGFs, Txk, AXL, BTK, and VEGFR2 with inhibition rates from $50 \%$ to $75 \%$, However, $25 \mathrm{~g}$ showed less than $50 \%$ inhibition of 25 other kinases (VEGFR1, 3, EPH-A2, -B2, IGF1R, FGFR1-4, JAK1, 3, Trk-A, -B, -C, ALK, IKK, RET, C-kit, and so on),

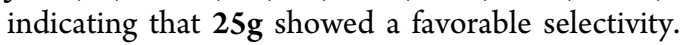

Then, we tested the antiproliferative activities of $\mathbf{2 5} \mathrm{g}$ against a panel of cell lines with different EGFR status. As shown in

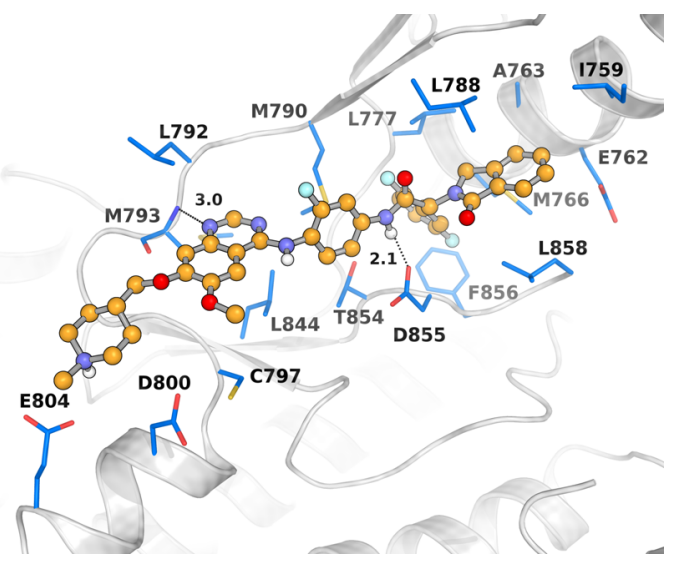

Figure 4. Docked pose of compound 25g. The EGFR protein (PDB: $5 \mathrm{~d} 41$ ) is shown as a gray cartoon, and the key residues are shown as blue sticks. Key H-bonds are displayed as black dashes and measured by distance. The figure was generated using Pymol 1.3.

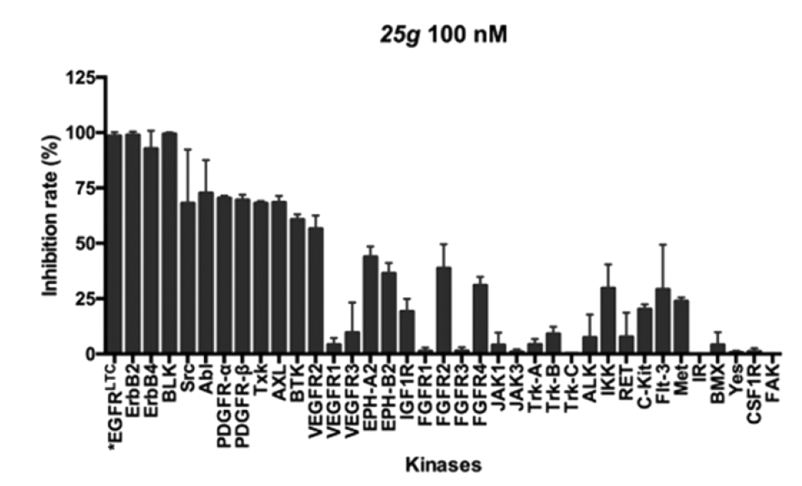

Figure 5. Kinase profile of $\mathbf{2 5 g}$ cross 37 kinases. ${ }^{2} \mathrm{EGFR}^{\mathrm{LTC}}$ : abbreviation for EGFR ${ }^{\mathrm{L} 85 \mathrm{R} / \mathrm{T} 790 \mathrm{M} / \mathrm{C} 797 \mathrm{~S}}$.

Table 1, 25g exhibited better antiproliferative effects against $\mathrm{BaF}_{3}-\mathrm{EGFR}^{\mathrm{L} 858 \mathrm{R} / \mathrm{T} 790 \mathrm{M} / \mathrm{C} 7975}$ cell lines than AZD9291 ( $\mathrm{IC}_{50}$ :

Table 1. In Vitro EGFR Antiproliferative Activity ${ }^{a}$

\begin{tabular}{lccc} 
& \multicolumn{3}{c}{ Antiproliferative $\mathrm{IC}_{50}(\mu \mathrm{M})$} \\
\cline { 2 - 4 } \multicolumn{1}{c}{ Cells } & $\mathbf{2 5 g}$ & AZD9291 & Brigatinib \\
$\mathrm{BaF}_{3}$ & $7.68 \pm 0.73$ & $5.11 \pm 0.49$ & $7.31 \pm 0.98$ \\
$\mathrm{BaF}_{3}-\mathrm{EGFR}^{\mathrm{L} 858 \mathrm{R} / \mathrm{T} 790 \mathrm{M} / \mathrm{C} 797 \mathrm{~S}}$ & $0.64 \pm 0.14$ & $3.93 \pm 0.38$ & $0.42 \pm 0.09$ \\
$\mathrm{H} 1975$ & $3.03 \pm 0.49$ & $0.03 \pm 0.01$ & $\mathrm{ND}^{b}$ \\
$\mathrm{~A} 431$ & $1.24 \pm 0.16$ & $1.44 \pm 0.03$ & $\mathrm{ND}^{b}$
\end{tabular}

${ }^{a}$ Antiproliferative activity was examined by the Resazurin assay or the SRB assay. Date are averages of at least three independent determinations and reported as the means \pm SD (standard deviations). ${ }^{b}$ Not determined.

$0.64 \mu \mathrm{M}$ vs $3.93 \mu \mathrm{M})$ and EAI045 $\left(\mathrm{IC}_{50}>10 \mu \mathrm{M}\right.$, Table S5, Supporting Information). Meanwhile, 25g showed moderate antiproliferative effects against the parental $\mathrm{BaF} 3$ cells $\left(\mathrm{IC}_{50}=\right.$ $7.68 \mu \mathrm{M}), \mathrm{H} 1975\left(\mathrm{IC}_{50}=3.03 \mu \mathrm{M}\right)$ cells, and A431 cells $\left(\mathrm{IC}_{50}\right.$ $=1.24 \mu \mathrm{M})$. Therefore, $25 \mathrm{~g}$ was selected as the $\mathrm{EGFR}^{\mathrm{L} 858 \mathrm{R} / \mathrm{T} 790 \mathrm{M} / \mathrm{C} 797 \mathrm{~S}}$ inhibitor for further study of cell signaling pathways.

The inhibitory activity of the representative compound $\mathbf{2 5 g}$ against the phosphorylation of EGFR was further confirmed by Western blot analysis. As shown in Figure 6, compound 25g dose-dependently inhibited the phosphorylation of EGFR in BaF3-EGFR ${ }^{\mathrm{L} 858 \mathrm{R} / \mathrm{T} 790 \mathrm{M} / \mathrm{C} 797 \mathrm{~S}}$ cells, while AZD9291 was unable 


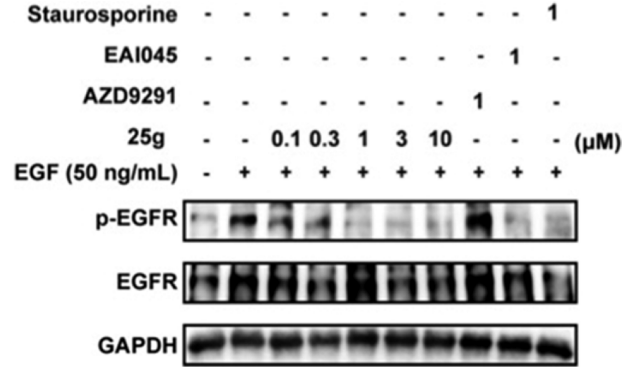

Figure 6. Bioactivity of $\mathbf{2 5 \mathrm { g }}$ on the phosphorylation of EGFR in BaF3-EGFR ${ }^{\mathrm{L} 858 \mathrm{R} / \mathrm{T} 790 \mathrm{M} / \mathrm{C} 797 \mathrm{~S}}$ cells.

to inhibit EGFR phosphorylation. Compound 25g showed significant inhibitory effects against p-EGFR at a concentration as low as $0.1 \mu \mathrm{M}$ and almost completely inhibited the phosphorylation of EGFR at a concentration of $1 \mu \mathrm{M}$, which was comparable to the potency of the fourth-generation allosteric inhibitor EAI045.

In addition, we also evaluated the potency of $\mathbf{2 5} \mathrm{g}$ against

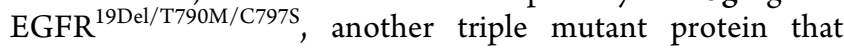
contains an exon 19 deletion activating mutation. The results showed that $\mathbf{2 5 g}$ exhibited weak activity against the $\mathrm{EGFR}^{19 \mathrm{Del} / \mathrm{T} 790 \mathrm{M} / \mathrm{C} 797 \mathrm{~S}}$ kinase, with an $\mathrm{IC}_{50}$ value of $331.3 \mathrm{nM}$ (Table S3) and weak antiproliferative activity against BaF3$\mathrm{EGFR}^{19 \mathrm{D} / \mathrm{T} 790 \mathrm{M} / \mathrm{C} 797 \mathrm{~S}}$ cells, with an $\mathrm{IC}_{50}$ value of $3.54 \mu \mathrm{M}$ (Table S4). Accordingly, 25g is more potent against $\mathrm{EGFR}^{\mathrm{L} 858 \mathrm{R} / \mathrm{T} 790 \mathrm{M} / \mathrm{C} 797 \mathrm{~S}}$ than against $\mathrm{EGFR}^{19 \mathrm{D} / \mathrm{T} 790 \mathrm{M} / \mathrm{C} 797 \mathrm{~S}}$.

We calculated some drug-likeness properties and tested the aqueous solubility of $\mathbf{2 5} \mathbf{g}$ (Table S7 and Table S8, Supporting Information). The results showed that $\mathbf{2 5 g}$ has poor solubility. Preliminary studies of in vivo pharmacokinetic (PK) properties of compound $25 \mathrm{~g}$ in rats following intravenous (IV) and oral (PO) administration (Table S6, Supporting Information) showed that $25 \mathrm{~g}$ has a high clearance rate $(\mathrm{CL}=960.8 \mathrm{~mL} /$ $\mathrm{h} / \mathrm{kg})$ and poor oral bioavailability $(F=0.55 \%)$.

\section{CONCLUSION}

Based on a report of the EGFR allosteric site ${ }^{19}$ and an iterative process of molecular docking, synthesis, and biological testing, we developed a series of potent and noncovalent reversible EGFR inhibitors that occupy both the ATP binding site and the allosteric site. The structure-activity relationships of this series of inhibitors were summarized against $\mathrm{EGFR}^{\mathrm{L} 858 \mathrm{R} / \mathrm{T} 790 \mathrm{M} / \mathrm{C} 797 \mathrm{~S}}$. One of the most promising compounds, $25 \mathrm{~g}$ inhibited the enzymatic activity of $\mathrm{EGFR}^{\mathrm{L} 858 \mathrm{R} / \mathrm{T} 790 \mathrm{M} / \mathrm{C} 797 \mathrm{~S}}$ with an $\mathrm{IC}_{50}$ value of $2.2 \mathrm{nM}$. Western

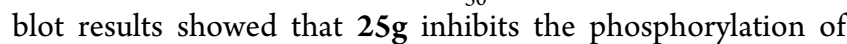
$\mathrm{EGFR}^{\mathrm{L} 858 \mathrm{R} / \mathrm{T} 790 \mathrm{M} / \mathrm{C} 797 \mathrm{~S}}$ and downstream signal transduction at the cellular level. Cell proliferation assays confirmed that $\mathbf{2 5 g}$ effectively and selectively inhibited the growth of $\mathrm{EGFR}^{\mathrm{L} 858 \mathrm{R} / \mathrm{T} 790 \mathrm{M} / \mathrm{C} 797 \mathrm{~S}}$-dependent cells. With the aim of further structural optimization to improve PK properties in the future, this series of compounds might serve as a good basis for the development of fourth-generation EGFR inhibitors of L858R/ T790M/C797S mutants.

\section{ASSOCIATED CONTENT}

\section{S Supporting Information}

The Supporting Information is available free of charge on the ACS Publications website at DOI: 10.1021/acsmedchemlett.8b00564.
The results of kinase activity assays for all the synthesized compounds and the methods used for docking simulations and chemical and biological assays (PDF)

The docked model of 25a with EGFR (PDB)

The docked model of $25 \mathrm{~g}$ with EGFR (PDB)

\section{AUTHOR INFORMATION}

\section{Corresponding Authors}

*E-mail: hlli@ecust.edu.cn (H.L.). Phone/Fax: +86-2164250213.

*E-mail: hxie@jding.dhs.org (H.X.). Phone: +86-2150805897.

*E-mail: yfxu@ecust.edu.cn (Y.X.). Phone: +86-21-64251399. ORCID ${ }^{\circ}$

Shiliang Li: 0000-0003-4414-237X

Honglin Li: 0000-0003-2270-1900

\section{Author Contributions}

${ }^{\S}$ Q.L., T.Z., and S.L. contributed equally to this work. All authors have given approval to the final version of the manuscript.

\section{Funding}

This work was supported by the National Key Research and Development Program [2016YFA0502304 to H.L.]; the National Natural Science Foundation of China (grant 81825020 to H.L., 81803437 to S.L.); the National Science \& Technology Major Project "Key New Drug Creation and Manufacturing Program”, China (Number: 2018ZX09711002); and Fundamental Research Funds for the Central Universities, Special Program for Applied Research on Super Computation of the NSFC-Guangdong Joint Fund (the second phase) under Grant No.U1501501. S.L. is sponsored by the Shanghai Sailing Program (No. 18YF1405100). H.L. is sponsored by the National Program for Special Support of Eminent Professionals and the National Program for Support of Top-notch Young Professionals.

\section{Notes}

The authors declare no competing financial interest.

\section{ABBREVIATIONS}

EGFR, epidermal growth factor receptor; NSCLC, nonsmall cell lung cancer; PK, pharmacokinetic; IV, intravenous; PO, oral.

\section{REFERENCES}

(1) Sharma, S. V.; Bell, D. W.; Settleman, J.; et al. Epidermal growth factor receptor mutations in lung cancer. Nat. Rev. Cancer 2007, 7, $169-181$.

(2) Shia, J.; Klimstra, D. S.; Li, A. R.; Qin, J.; Saltz, L.; TeruyaFeldstein, J.; Akram, M.; Chung, K. Y.; Yao, D.; Paty, P. B.; Gerald, W.; Chen, B. Epidermal growth factor receptor expression and gene amplification in colorectal carcinoma: an immunohistochemical and chromogenic in situ hybridization study. Mod. Pathol. 2005, 18, $1348-1350$.

(3) Wang, X.; Zhang, S.; MacLennan, G. T.; Eble, J. N.; LopezBeltran, A.; Yang, X. J.; Pan, C.-X.; Zhou, H.; Montironi, R.; Cheng, L. Epidermal growth factor receptor protein expression and gene amplification in small cell carcinoma of the urinary bladder. Clin. Cancer Res. 2007, 13 (3), 953-957.

(4) Perez, E. A. The role of adjuvant monoclonal antibody therapy for breast cancer: rationale and new studies. Curr. Oncol. Rep. 2001, 3 (6), 516-522. 
(5) Torre, L. A.; Bray, F.; Siegel, R. L.; Ferlay, J.; Lortet-Tieulent, J.; Jemal, A. Global cancer statistics. Ca-Cancer J. Clin. 2015, 65 (2), 87108.

(6) Cohen, M. H.; Williams, G. A.; Sridhara, R.; Chen, G.; McGuinn, W. D.; Morse, D.; Abraham, S.; Rahman, A.; Liang, C.; Lostritto, R.; Baird, A.; Pazdur, R. United States Food and Drug Administration Drug Approval summary: Gefitinib (ZD1839; Iressa) tablets. Clin. Cancer Res. 2004, 10 (4), 1212-1218.

(7) Xu, Y.; Liu, H.; Chen, J.; Zhou, Q. Acquired resistance of lung adenocarcinoma to EGFR-tyrosine kinase inhibitors gefitinib and erlotinib. Cancer Biol. Ther. 2010, 9 (8), 572-582.

(8) Tiseo, M.; Bartolotti, M.; Gelsomino, F.; Bordi, P. Emerging role of gefitinib in the treatment of non-small-cell lung cancer (NSCLC). Drug Des., Dev. Ther. 2010, 81-98.

(9) Gazdar, A. F. Activating and resistance mutations of EGFR in non-small-cell lung cancer: role in clinical response to EGFR tyrosine kinase inhibitors. Oncogene 2009, 28, S24-S31.

(10) Yu, H. A.; Arcila, M. E.; Rekhtman, N.; Sima, C. S.; Zakowski, M. F.; Pao, W.; Kris, M. G.; Miller, V. A.; Ladanyi, M.; Riely, G. J. Analysis of tumor specimens at the time of acquired resistance to EGFR-TKI therapy in 155 patients with EGFR-mutant lung cancers. Clin. Cancer Res. 2013, 19 (8), 2240-2247.

(11) Yun, C.-H.; Mengwasser, K. E.; Toms, A. V.; Woo, M. S.; Greulich, H.; Wong, K.-K.; Meyerson, M.; Eck, M. J. The T790M mutation in EGFR kinase causes drug resistance by increasing the affinity for ATP. Proc. Natl. Acad. Sci. U. S. A. 2008, 105 (6), 20702075.

(12) Zhou, W.; Ercan, D.; Chen, L.; Yun, C.-H.; Li, D.; Capelletti, M.; Cortot, A. B.; Chirieac, L.; Iacob, R. E.; Padera, R.; Engen, J. R.; Wong, K.-K.; Eck, M. J.; Gray, N. S.; Jänne, P. A. Novel mutantselective EGFR kinase inhibitors against EGFR T790M. Nature 2009, 462 (7276), 1070-1074.

(13) Singh, M.; Jadhav, H. Targeting non-small cell lung cancer with small-molecule EGFR tyrosine kinase inhibitors. Drug Discovery Today 2018, 23 (3), 745-753.

(14) Zhang, L.; Yang, Y. Y.; Zhou, H. J.; Zheng, Q. M.; Li, Y. H.; Zheng, S. S.; Zhao, S. Y.; Chen, D.; Fan, C. W. Structure-activity study of quinazoline derivatives leading to the discovery of potent EGFRT790M inhibitors. Eur. J. Med. Chem. 2015, 102, 445-463.

(15) Ward, R. A.; Anderton, M. J.; Ashton, S.; Bethel, P. A.; Box, M.; Butterworth, S.; Colclough, N.; Chorley, C. G.; Chuaqui, C.; Cross, D. A. E.; Dakin, L. A.; Debreczeni, J. É.; Eberlein, C.; Finlay, M. R. V.; Hill, G. B.; Grist, M.; Klinowska, T. C. M.; Lane, C.; Martin, S.; Orme, J. P.; Smith, P.; Wang, F.; Waring, M. J. Structure- and reactivity-based development of covalent inhibitors of the activating and gatekeeper mutant forms of the epidermal growth factor receptor (EGFR). J. Med. Chem. 2013, 56, 7025-7048.

(16) Finlay, M. R.; Anderton, M.; Ashton, S.; Ballard, P.; Bethel, P. A.; Box, M. R.; Bradbury, R. H.; Brown, S. J.; Butterworth, S.; Campbell, A.; Chorley, C.; Colclough, N.; Cross, D.; Currie, G.; Grist, M.; Hassall, L.; Hill, G. B.; James, G.; James, M.; Kemmitt, P.; Klinowska, T.; Lamont, G.; Lamont, S. G.; Martin, N.; McFarland, H. L.; Mellor, M. J.; Orme, J. P.; Perkins, D.; Perkins, P.; Richmond, G.; Smith, P.; Ward, R. A.; Waring, M. J.; Whittaker, D.; Wells, S.; Wrigley, G. Discovery of a potent and selective EGFR inhibitor (AZD9291) of both sensitizing and T790M resistancemutations that spares the wild type form of the receptor. J. Med. Chem. 2014, 57 (20), 8249-67.

(17) Planchard, D.; Brown, K. H.; Kim, D.-W.; Kim, S.-W.; Ohe, Y.; Felip, E.; Leese, P.; Cantarini, M.; Vishwanathan, K.; Jänne, P. A.; Ranson, M.; Dickinson, P. A. Osimertinib Western and Asian clinical pharmacokinetics in patients and healthy volunteers: implications for formulation, dose, and dosing frequency in pivotal clinical studies. Cancer Chemother. Pharmacol. 2016, 77 (4), 767-776.

(18) Eberlein, C. A.; Stetson, D.; Markovets, A. A.; Al-Kadhimi, K. J.; Lai, Z.; Fisher, P. R.; Meador, C. B.; Spitzler, P.; Ichihara, E.; Ross, S. J.; Ahdesmaki, M. J.; Ahmed, A.; Ratcliffe, L. E.; O’Brien, E. L. C.; Barnes, C. H.; Brown, H.; Smith, P. D.; Dry, J. R.; Beran, G.; Thress, K. S.; Dougherty, B.; Pao, W.; Cross, D. A. E. Acquired Resistance to the Mutant-Selective EGFR Inhibitor AZD9291 Is Associated with Increased Dependence on RAS Signaling in Preclinical Models. Cancer Res. 2015, 75 (12), 2489-2500.

(19) Jia, Y.; Yun, C.-H.; Park, E.; Ercan, D.; Manuia, M.; Juarez, J.; Xu, C.; Rhee, K.; Chen, T.; Zhang, H.; Palakurthi, S.; Jang, J.; Lelais, G.; DiDonato, M.; Bursulaya, B.; Michellys, P.-Y.; Epple, R.; Marsilje, T. H.; McNeill, M.; Lu, W.; Harris, J.; Bender, S.; Wong, K.-K.; Jänne, P. A.; Eck, M. J. Overcoming EGFR(T790M) and EGFR(C797S) resistance with mutant-selective allosteric inhibitors. Nature 2016, 534 (7605), 129-132.

(20) Morabito, A.; Piccirillo, M. C.; Falasconi, F.; De Feo, G.; Del Giudice, A.; Bryce, J.; Di Maio, M.; De Maio, E.; Normanno, N.; Perrone, F. Vandetanib (ZD6474), a dual inhibitor of vascular endothelial growth factor receptor (VEGFR) and epidermal growth factor receptor (EGFR) tyrosine kinases: current status and future directions. Oncologist 2009, 14 (4), 378-390.

(21) Garofalo, A.; Goossens, L.; Lemoine, A.; Farce, A.; Arlot, Y.; Depreux, P. Quinazoline-urea, new protein kinase inhibitors in treatment of prostate cancer. J. Enzyme Inhib. Med. Chem. 2010, 25 (2), 158-171.

(22) Chen, L.; Fu, W.; Zheng, L.; et al. Recent progress of smallmolecule epidermal growth factor receptor (EGFR) inhibitors against C797S resistance in non-small-cell lung cancer. J. Med. Chem. 2018, 61, 4290-4300. 